Bull. Chem. Soc. Ethiop. 2016, 30(1), 27-37.

Printed in Ethiopia

ISSN 1011-3924

DOI: http://dx.doi.org/10.4314/bcse.v30i1.3

(c) 2016 Chemical Society of Ethiopia

\title{
TOTAL CONTENTS OF PHENOLICS, FLAVONOIDS, TANNINS AND ANTIOXIDANT CAPACITY OF SELECTED TRADITIONAL ETHIOPIAN ALCOHOLIC BEVERAGES
}

\author{
Ayalew Debebe ${ }^{1,2}$, Bhagwan Singh Chandravanshi ${ }^{1 *}$ and Mesfin Redi-Abshiro ${ }^{1}$ \\ ${ }^{1}$ Department of Chemistry, Addis Ababa University, P.O. Box 1176, Addis Ababa, Ethiopia \\ ${ }^{2}$ Department of Chemistry, Haramaya University, P.O. Box 138, Dire Dawa, Ethiopia
}

(Received April 3, 2015; revised November 29, 2015)

\begin{abstract}
The aim of this study was to determine the total contents of phenolics, tannins and flavonoids and antioxidant capacity and their relationships in traditional Ethiopian alcoholic beverages. They have been determined utilizing Folin-Ciocalteu assay, aluminum chloride precipitating agent and 2,2-diphenyl-1picrylhydrazyl (DPPH) assay, respectively. The most widely consumed beverages and which have many varieties were selected for this study. These are gesho fermented and non-gesho beverages tella, tej, borde, keribo, birz, korefe and areke. The total phenolic content obtained in gallic acid equivalent (GAE) $\mu \mathrm{g} \mathrm{mL}{ }^{-1}$ was: areke $(0.2-$ $0.62)$, tella (10.1-19.1), tej (5.8-9.5), keribo (10.4-14.9), birz (10.5-12.2), korefe (9.2-10.7) and borde (8.410.6). The majority of phenolic compounds in the alcoholic beverages are non-tannic and non-flavonoid compounds. The antioxidant capacity obtained in ascorbic acid equivalent (AAE) $\mu \mathrm{g} \mathrm{mL}{ }^{-1}$ was: areke $(-0.28-284)$, tella (31.6-201), tej (1.73-73.7), keribo (39.21-90.11), birz (41.95-63.08), korefe (58.25-96.45) and borde (180217). The variation in the antioxidant activity among the beverages is due to the types and amount of ingredients used, disparity in the preparation process and the types of phenolic compounds found. The relationship between total phenolics and antioxidant activities was investigated using Pearson correlation at $95 \%$ confidence level. The results obtained indicate that the non-gesho fermented beverages such as keribo $(-0.714)$, birz $(-0.686)$ and borde $(-0.212)$ have negative antioxidant correlation with the total phenolic, whereas, fermented beverages with gesho such as tella (0.539), tej (0.385) and korefe (0.557) have positive correlations. Areke has an overall positive correlation (0.609), but, the cereal areke which does not have medicinal plants has negative correlation.
\end{abstract}

KEY WORDS: Phenolic content, Antioxidant capacity, Traditional alcoholic beverages, Ethiopian beverages

\section{INTRODUCTION}

Traditional alcoholic beverages, tella, tej, keribo, birz, borde, korefe and areke are indigenous to Ethiopia [1]. Areke is distilled whereas the rest are fermented alcoholic beverages [2-4]. Tella and korefe (a malt beverage like beer) are made from a mixture of enkuro (a dark brown toasted flour of barely, maize or sorghum), germinated wheat grain (bikil), gesho (Rhamnus prenoids) and water [4]. Tej and birz (honey beer) are prepared from honey and water. But, tej has leaves or stem of gesho (Rhamnus prenoides) as an additional ingredient [2,4]. Borde and keribo are made from a mixture of roasted grain (barely, wheat, maize or sorghum) and their malts $[4,5]$. Areke is a colorless, clear, distilled traditional alcoholic beverage which is prepared in almost the same way as tella [3]. The beverages were selected by two major points. One they are the most widely consumed beverages. Second, the beverages especially the distilled, areke has many varieties.

Alcoholic beverages beside their main components, ethanol and water, contain a large number of minor compounds such as phenolics [6-8]. The characteristics of alcoholic beverages are determined by their chemical composition [9]. In this sense, phenolic compounds have impacts in alcoholic beverages quality [9].

Phenolic compounds, the secondary metabolites, are widely distributed in a variety of beverages [8]. Natural phenolic compounds can range from simple molecules, such as phenolic

*Corresponding author. E-mail: bscv2006@yahoo.com 
acids, to highly polymerised compounds, such as tannins [10]. Phenolic compounds, i.e. anthocyanins, resveratrol, gallic acid, catechin, myricetin, quercetin, etc. are abundant in red wines [11]. They occur primarily in conjugated form, with one or more sugar residues linked to hydroxyl groups, although direct linkages of the sugar unit to an aromatic carbon atom also exist [10]. The presence of phenolic compounds in plant foods is largely influenced by genetic factors and environmental conditions. Other factors such as germination, degree of ripeness, variety, processing, and storage also influence the content of plant phenolics [10, 12].

Phenolic compounds are important components of beverages, to which they contribute flavor, color, and sensory properties such as bitterness and astringency [9, 11, 13-15], aroma and haze formation during storage [9]. Moreover, phenolic compounds are known to play an important role in alcoholic beverages making processes, since they participate in clarification, and present an inhibiting effect on spoilage micro-organisms, as well as, on clarification enzymes $[9,11]$.

In contrast to their ability of reducing food digestibility caused by the potential phenolics to bind and precipitate macromolecules; interest in food phenolics has increased, because of their antioxidant and free radical scavenging abilities [10], metal chelators and enzyme modulators [11]. Many phenolics can exhibit antioxidant activity as their extensive, conjugated $\pi$-electron systems allow ready donation of electrons, or hydrogen atoms, from the hydroxyl moieties to free radicals. However, the antioxidant efficacy, in terms of reaction stoichiometry and reaction kinetics may vary considerably [10]. This is dependent on structural features, such as the number and positions of the hydroxyl moieties on the ring systems, and the extent by which the unpaired electron in the oxidized phenolic intermediate can delocalise throughout the molecule. Thus, most phenolics, especially flavonoids are very effective scavengers of hydroxyl and peroxyl radicals. Phenolics are chelators of metals and inhibit the Fenton and Haber-Weiss reactions $[10,11]$, which are important sources of active oxygen radicals. In addition, flavonoids retain their free radical scavenging capacity after forming complexes with metal ions [10]. On account of their antioxidant effects, phenolic compounds inhibit the development of cancerous tumours, reduce a risk for cardiovascular disease, and have showed anti-bacterial, antiinflammatory, anti-spasmodic and anti-diarrhoeic properties [16].

Total phenolic compounds in liqueurs made from red fruits [17], wine [18-21], worts and beer [13, 22, 23], traditional fermented sorghum beers "dolo" [16], alcoholic beverages made from purple rice [24], ciders [25] and spirit drinks [26]; anthocyanins in liqueurs made from red fruits [17], dolo [16] and wine [21]; total flavonoids in wines [21]; and antioxidants capacity in wine [12, 18, 20, 21], beer [23], liqueurs made from red fruit [17], alcoholic beverages made from purple rice [24] were determined.

Ethiopian alcoholic beverages, their types [4, 27], preparation $[1,4,5,27,28]$, alcoholic contents [4, 27, 28], and physico-chemical properties [27, 28-30] were studied. These are summarized in Table 1 for the studied beverages (Table 1). Nevertheless, there is no any report on the total phenolics, total flavonoids, total tannins and antioxidant capacity of Ethiopian alcoholic beverages. Moreover, there is no any report on the total tannin contents of alcoholic beverages in general.

Phenolic compounds have tremendous importance. Traditionally, the Ethiopian alcoholic beverages areke and tej have been used as medicine. However, data on their phenolics and antioxidant effects are scarce. Therefore, the objectives of present work were to: (i) determine the total phenolic, total flavonoid and total tannin contents, (ii) study the antioxidant characteristics, (iii) establish the relationship between the characteristics mentioned and (iv) develop a procedure for total tannin determination in some selected traditional alcoholic beverages. To the best of our knowledge, this study represents the first of its kind on total phenolics and related assays and antioxidant effects of Ethiopian traditional alcoholic beverages. 
Table 1. Physico-chemical properties, raw materials and production process of some Ethiopian traditional beverages.

\begin{tabular}{|c|c|c|c|c|c|}
\hline S. No. & Samples & $\begin{array}{l}\text { Physico-chemical } \\
\text { properties }\end{array}$ & Raw materials & Production process & Reference \\
\hline 1 & $\begin{array}{l}\text { Tella, } \\
\text { Korefe }\end{array}$ & $\begin{array}{l}\text { Dark brown in } \\
\text { color } \\
\mathrm{pH} 4-5\end{array}$ & $\begin{array}{l}\text { Kita (a thin, 5-10 mm thick, } \\
\text { pancake-like bread), enkuro (a } \\
\text { dark brown toasted flour), } \\
\text { bikil (germinated grain), } \\
\text { powdered gesho (Rhamnus } \\
\text { prenoids) }\end{array}$ & $\begin{array}{l}\text { A four phase } \\
\text { fermentation for 10-12 } \\
\text { days }\end{array}$ & 4,28 \\
\hline 2 & $T e j$ & $\begin{array}{l}\text { Yellow, sweet, } \\
\text { effervescent and } \\
\text { cloudy } \\
\text { pH 3.07-4.90 }\end{array}$ & $\begin{array}{l}\text { Honey or mixture of sugar } \\
\text { with honey and leaves of } \\
\text { gesho (Rhamnus prenoides) }\end{array}$ & $\begin{array}{l}\text { Mixing boiled must } \\
\text { (with gesho (Rhamnus } \\
\text { prenoides) and } \\
\text { unboiled must and then } \\
\text { allow to ferment for } 5 \\
\text { days in warm or for } 15- \\
20 \text { days in colder } \\
\text { weather } \\
\end{array}$ & 2,4 \\
\hline 3 & Birz & $\begin{array}{l}\text { Yellow, sweet, } \\
\text { effervescent and } \\
\text { cloudy }\end{array}$ & $\begin{array}{l}\text { Honey or mixture of sugar } \\
\text { with honey }\end{array}$ & $\begin{array}{l}\text { Has a short } \\
\text { fermentation period, } \\
\text { usually overnight }\end{array}$ & 4 \\
\hline 4 & Borde & $\begin{array}{l}\text { Opaque, } \\
\text { effervescent, } \\
\text { whitish-grey to } \\
\text { brown coloured } \\
\text { with a thick } \\
\text { consistency and a } \\
\text { sweet-sour taste }\end{array}$ & $\begin{array}{l}\text { Unmalted maize (Zea mays), } \\
\text { barley (Hordeum vuldare), } \\
\text { wheat (Triticum sativum), } \\
\text { finger millet (Eleusine } \\
\text { coracana), sorghum (Sorghum } \\
\text { bicolor) and/or tef (Eragrostis } \\
\text { tef) and their malt; additional } \\
\text { ingredients, garlic, fresh chili } \\
\text { (Capsicum minimum), ginger } \\
\text { and salt }\end{array}$ & $\begin{array}{l}\text { A four phase } \\
\text { fermentation for less } \\
\text { than } 4 \text { days }\end{array}$ & $1,4,27$ \\
\hline 5 & Keribo & \begin{tabular}{|l} 
Dark brown \\
coloured \\
pH 3.20-5.17
\end{tabular} & $\begin{array}{l}\text { Unmalted roasted barley } \\
\text { (Hordeum vuldare), sugar and } \\
\text { yeast }\end{array}$ & $\begin{array}{l}\text { Has a short } \\
\text { fermentation period, } \\
\text { usually overnight }\end{array}$ & 5 \\
\hline 6 & Areke & $\begin{array}{l}\text { Clear and colorless } \\
\text { (sometimes } \\
\text { colorful) } \\
\text { pH 4.30-4.51 }\end{array}$ & $\begin{array}{l}\text { Kita (a thin, } 5-10 \mathrm{~mm} \text { thick, } \\
\text { pancake-like bread), bikil } \\
\text { (germinated grain), powdered } \\
\text { gesho (Rhamnus prenoids); } \\
\text { additional ingredients, koso } \\
\text { (Hagenia abyssinica), gibto } \\
\text { (Lupinus albu or white lupin), } \\
\text { mar (honey), and tenaadam } \\
\text { (Ruta chalepensis) }\end{array}$ & $\begin{array}{l}\text { Fermentation in the } \\
\text { same way as tella and } \\
\text { then distillation }\end{array}$ & 4,28 \\
\hline
\end{tabular}

\section{EXPERIMENTAL}

Chemicals

Folin-Ciocalteu's reagent (BDH Chemicals Ltd, Poole, England), 2,2 diphenyl-1-picrylhydrazyl, DPPH (Sigma Aldrich, Steinheim, Germany), sodium tungstate (BDH Laboratory Supplies, Poole, England), sodium molybdate dehydrate (BDH Laboratory Supplies, Poole, England), lithium sulfate (BDH Chemicals Ltd, Poole, England), bromine water (Guandong Guanghua Chemical Factory Co. Ltd, China), lithium sulfate anhydrous (Research-Lab Fine Chem 
Industries, Mumbai, India), sodium carbonate (Reaserch-Lab Fine Chem Industries, Mumbai, India), gallic acid (Sigma Aldrich, Steinheim, Germany), ascorbic acid (BDH Chemicals Ltd, Poole, England), catechin (Sigma-Aldrich, Steinheim, Germany), aluminium chloride (SigmaAldrich, Steinheim, Germany), sodium nitrite (Sigma-Aldrich, Steinheim, Germany), sodium hydroxide (Scharlau Chemie S.A., Eurprean Union), egg albumin (BDH Chemical Ltd, Poole, England), tannic acid (Sigma Aldrich, Steinheim, Germany), acetate buffer (prepared using acetic acid and sodium acetate, BDH Laboratory Supplies, Poole, England) and sodium chloride (Sigma Aldrich, Steinheim, Germany).

\section{Instruments}

Spectrophotometric measurements were performed on a UV-Vis spectrophotometer (Lambda 950, Perkin Elmer, UK) equipped with 1-cm path length quartz cells.

\section{Beverages sampling}

For this study, seven most popular Ethiopian alcoholic beverages, tej (honey wine), tella (a malt beverage like beer), areke (distilled beverage), keribo, birz, borde, and korefe were selected. A total of 49 fermented beverages samples: 15 tej, 15 tella, 3 borde, 4 birz, 6 korefe and 6 keribo were collected randomly from vending houses at different sub-cities of Addis Ababa, the capital city of Ethiopia and from five nearby towns (Sebeta, Dukem, Sululta, Sendafa, and Burayu) of Oromia Regional State and 15 Areke (distilled beverage) from Addis Ababa and other potential producing areas such as Arsi Negele (Ormiya Regional State), Butagira (SNNPR Regional State) and Debere Birhan (Amhara Regional State). The collected samples of areke include: Yekoso (Hagenia abyssinica), Cereal (only cereal based), and Yegibto (Lupinus albu or white lupin), Yemar (honey), Yetenaadam (Ruta chalepensis). $150 \mathrm{~mL}$ of fermented beverages of each type were taken from the three places of a particular site and then $450 \mathrm{~mL}$ bulk samples were prepared. Likewise, $250 \mathrm{~mL}$ of the beverages were taken and then, $750 \mathrm{~mL}$ bulk samples were prepared for distilled beverages. All the areke samples except cereal based have additional ingredient as their names indicate. All the samples were collected using glass amber bottles and kept at $4{ }^{\circ} \mathrm{C}$ until the analysis time. For liquid samples such as tella, tej, birz, keribo and areke no sample pretreatment was made except filtration, whereas, for semi-liquid samples such as borde and korefe extraction and filtration were done.

\section{Phenolic compounds extraction}

For the extraction of phenolic compounds, several solvents have been employed. The solvents used were acetone, chloroform, ethanol, methanol, ethyl acetate, $80 \%$ acetone, $80 \%$ ethanol and $80 \%$ methanol. The preliminary assays showed that the best extraction was achieved with ethyl acetate. The extraction time $(30-150 \mathrm{~min})$ and the volume of extraction solvent (ethyl acetate) $(5-25 \mathrm{~mL})$ and centrifugation time $(5,10$ and $15 \mathrm{~min})$ were recorded. The optimal results were achieved using $10 \mathrm{~mL}$ sample, $10 \mathrm{~mL}$ ethyl acetate, 120 min reaction time and $10 \mathrm{~min}$ centrifugation.

\section{Total phenolic content}

The total phenolic content in the samples/extracts was determined by the Folin-Ciocalteu colorimetric method using gallic acid as the standard [31]. The method is based on the reduction of phosphotungstate-phophomolybdate complex by phenolics to blue reaction products [22]. The modified method in brief, $0.1 \mathrm{~mL}$ of sample/standard solution $(500,250,125,62.5,31.25$ and $\left.15.63 \mu \mathrm{g} \mathrm{mL}^{-1}\right)$ in $5 \%(\mathrm{v} / \mathrm{v})$ methanol was mixed with $1 \mathrm{~mL}$ Folin-Ciocalteu reagent $(1: 9$ 
diluted with water) and after $5 \min 1 \mathrm{~mL} 10 \%$ (w/v) $\mathrm{Na}_{2} \mathrm{CO}_{3}$ was added. The mixture was diluted with $8.4 \mathrm{~mL}$ de-ionized water. The spectrum was scanned against blank using spectrophotometer from 1396-400 $\mathrm{nm}$ after $90 \mathrm{~min}$ of incubation at room temperature. The concentration of total phenolic compounds was expressed in microgram of gallic acid equivalent (GAE) per milliliter using the calibration curve equation, $\mathrm{y}=0.36397 \mathrm{x}+0.0287$ (where $\mathrm{y}=$ absorbance and $\mathrm{x}=$ concentration, GAE in $\mu \mathrm{g} \mathrm{mL}^{-1}$ ). The absolute absorbance was taken around $760 \mathrm{~nm}$ (Abs at $\max ^{-}$Abs at base) against an appropriate blank. All samples were analyzed in triplicates.

\section{Antioxidant assays}

The evaluation of antioxidant capacity may vary according to the methods used [16]. The antioxidant capacity can be estimated with 2,2-diphenyl-1-picrylhydrazyl (DPPH) assay, trolox equivalent antioxidant capacity (TEAC) assay using 2,2'-azinobis(3-ethylbenzothiazoline-6sulfonic acid radical) [16] and ferric reducing/antioxidant power (FRAP) assay [32]. In this study DPPH assay was used. This test is based on the capacity of stable free radical 2,2diphenyl-1-picrylhydrazyl to react with hydrogen $(\mathrm{H})$ donors, including phenols. It is used for the quantification of antioxidants in the complex of biological systems, beverages [16].

For this routine assay, $160 \mu \mathrm{g} \mathrm{mL}^{-1} \mathrm{DPPH}$ solution in methanol was prepared. The solution was vortexed vigorously until all DPPH was dissolved. Afterward, $2 \mathrm{~mL}$ of $160 \mu \mathrm{g} \mathrm{mL}^{-1} \mathrm{DPPH}$ was mixed with $1 \mathrm{~mL}$ of ascorbic acid standards $\left(25,12.5,6.25,3.13\right.$ and $\left.1.56 \mu \mathrm{g} \mathrm{mL}^{-1}\right)$ per alcoholic beverage samples, and $3 \mathrm{~mL}$ of methanol. The mixture was allowed to react at room temperature in the dark for one hour. The positive control assays were prepared with $2 \mathrm{~mL}$ of DPPH solution and $4 \mathrm{~mL}$ of methanol only. The absorbance values of the compounds changing from violet to yellow color were measured at $517 \mathrm{~nm}$. Quantification of antioxidant capacity was made by calibration curves obtained from methanolic solutions of ascorbic acid; the antioxidant capacity of compounds was expressed as microgram of ascorbic acid equivalent (AAE) using the calibration curve equation, $\mathrm{y}=18.23 \mathrm{x}+17.66$ (where $\mathrm{y}=$ absorbance and $\mathrm{x}=$ concentration, AAE in $\left.\mu \mathrm{g} \mathrm{mL}^{-1}\right)$. All samples were analyzed in triplicates.

\section{Total flavonoid content}

The total flavonoid concentration was measured using a colorimetric assay [32]. Catechin standard solutions were prepared by dissolving catechin in water at a concentration ranging from 10 to $50 \mu \mathrm{g} \mathrm{mL}^{-1}$. Briefly, $1 \mathrm{~mL}$ of appropriately diluted aqueous catechin standard solutions or beverage sample was added to $4 \mathrm{~mL}$ of distilled water. At time zero, $0.3 \mathrm{~mL}$ of $5 \%$ (w/v) $\mathrm{NaNO}_{2}$ was added. $0.3 \mathrm{~mL}$ of $10 \%(\mathrm{w} / \mathrm{v}) \mathrm{AlCl}_{3}$ was added 5 min later. At $6 \mathrm{~min}, 2 \mathrm{~mL}$ of $1 \mathrm{~mol} \mathrm{~L}^{-1} \mathrm{NaOH}$ was added and the solution was made up to $10 \mathrm{~mL}$ with distilled water and mixed. The spectrum was scanned against blank using spectrophotometer from 850-290 nm. The absolute absorbance (Abs at ${ }_{500}-$ Abs at ${ }_{\text {base }}$ ) was against an appropriate blank. The total flavonoid content was expressed in micrograms of catechin equivalent per millilitre with calibration equation of $y=0.02228 x+0.06345(y=$ absorbance and $x=$ concentration, CE in $\mu \mathrm{g}$ $\left.\mathrm{mL}^{-1}\right)$. All samples were analyzed in triplicate.

\section{Total tannin content}

The total tannin determination in alcoholic beverages was developed using egg albumin solution and Folin-Ciocalteu reagent as a precipitating reagent and color forming moiety, respectively. In this case the indirect approach was followed. That is, total polyphenolic compounds were determined using Folin-Ciocalteu method. For the determination of total tannin, first the same sample/extract was treated with $2 \mathrm{~mL}$ egg albumin $\left(25 \mathrm{mg} \mathrm{L}^{-1}\right)$ solution under optimized 
conditions ( $1: 5$ concentration ratio, $3.5 \mathrm{pH}, 1$ hour reaction time and 10 min centrifugation). 0.5 $\mathrm{mL}, 0.1 \mathrm{~mL}$ and $0.02 \mathrm{~mL}$ were taken for tella, borde, korefe and keribo; tej and birz; and areke samples, respectively. Then, the tannin-protein precipitate was separated via centrifugation and the supernatant (the non-tannin solution) was treated with Folin-Ciocalteu method as stated above. The difference in absorbance value before and after tannin removal was regarded as absorbance value of total tannins. All samples were analyzed in triplicate.

\section{Statistical analysis}

In this study, a one way ANOVA and Pearson correlation coefficient were used at 95\% confidence level using SPSS software to know the variation between samples analyzed was significant or not.

\section{RESULTS AND DISCUSSION}

Quantities of total phenol and related assays and antioxidant capacity

Distilled beverage, areke

Levels of phenolic content are expressed in terms of gallic acid equivalent (GAE). The total phenolic content was determined by the method of Folin-Ciocalteu from calibration curve equation.

Table 2. Total phenolics, total flavonoids, total tannins and antioxidant capacity of areke samples.

\begin{tabular}{|l|c|c|c|c|}
\hline Types of samples & $\begin{array}{c}\text { Total phenolics } \\
{\left[\mu \mathrm{g} \mathrm{mL} \mathrm{m}^{-1} \mathrm{GAE}\right]}\end{array}$ & $\begin{array}{c}\text { Total flavonoids } \\
{\left[\mu \mathrm{gL}^{-1} \mathrm{CE}\right]}\end{array}$ & $\begin{array}{c}\text { Total tannins } \\
{\left[\mu \mathrm{mL}^{-1} \mathrm{GAE}\right]}\end{array}$ & $\begin{array}{c}\text { Antioxidant } \\
\text { capacity } \\
{\left[\mu \mathrm{mL}^{-1} \mathrm{AAE}\right]}\end{array}$ \\
\hline Arsi Negele Cereal & $0.25 \pm 0.0008$ & $0.08 \pm 0.004$ & $0.01 \pm 0.006$ & $0.19 \pm 0.10$ \\
\hline Arsi Negele Yekosso & $0.26 \pm 0.0014$ & $0.08 \pm 0.007$ & $0.01 \pm 0.033$ & $271 \pm 2$ \\
\hline Butagera Cereal & $0.22 \pm 0.0045$ & $0.07 \pm 0.004$ & $0.05 \pm 0.009$ & $-4.80 \pm 0.06$ \\
\hline Butagera Yekosso & $0.20 \pm 0.0003$ & $0.07 \pm 0.003$ & $0.02 \pm 0.001$ & $-1.49 \pm 0.05$ \\
\hline Addis Ababa Cereal & $0.22 \pm 0.0002$ & $0.07 \pm 0.001$ & $0.07 \pm 0.003$ & $-2.87 \pm 0.03$ \\
\hline Addis Ababa Yekosso & $0.26 \pm 0.0007$ & $0.08 \pm 0.008$ & $0.08 \pm 0.011$ & $-1.61 \pm 0.04$ \\
\hline Addis Ababa Yegibto & $0.27 \pm 0.0015$ & $0.07 \pm 0.011$ & $0.04 \pm 0.003$ & $0.62 \pm 0.02$ \\
\hline Debre Birhan Cereal & $0.22 \pm 0.0009$ & $0.07 \pm 0.006$ & $0.04 \pm 0.003$ & $-0.86 \pm 0.06$ \\
\hline Debre Birhan Yekosso (white) & $0.27 \pm 0.0017$ & $0.06 \pm 0.005$ & $0.00 \pm 0.002$ & $-3.39 \pm 0.04$ \\
\hline Debre BirhanYekosso (brown) & $0.40 \pm 0.0000$ & $0.11 \pm 0.197$ & $0.05 \pm 0.001$ & $256 \pm 4$ \\
\hline Debre Birhan Yemar & $0.62 \pm 0.0021$ & $0.07 \pm 0.001$ & $0.03 \pm 0.001$ & $284 \pm 3$ \\
\hline Debre Tsige Cereal & $0.21 \pm 0.0001$ & $0.07 \pm 0.003$ & $0.08 \pm 0.005$ & $10.6 \pm 0.01$ \\
\hline Debre BirhanYenechshinkurt & $0.24 \pm 0.0019$ & $0.12 \pm 0.022$ & $0.02 \pm 0.001$ & $249 \pm 0.1$ \\
\hline Dembecha Yegibto & $0.32 \pm 0.0008$ & $0.07 \pm 0.001$ & $0.04 \pm 0.002$ & $217 \pm 2$ \\
\hline Dembecha Dagim & $0.27 \pm 0.0032$ & $0.07 \pm 0.015$ & $0.06 \pm 0.002$ & $220 \pm 4$ \\
\hline
\end{tabular}

Total phenolics, total flavonoids, total tannins and antioxidant capacity of areke samples ranged from $0.20-0.62 \mu \mathrm{g} \mathrm{mL}{ }^{-1} \mathrm{GAE}, 0.06-0.12 \mu \mathrm{g} \mathrm{mL}^{-1} \mathrm{CE}, 0.02-0.08 \mu \mathrm{g} \mathrm{mL}^{-1} \mathrm{GAE}$ and $-0.86-284 \mu \mathrm{g} \mathrm{mL}^{-1}$ AAE with average values $0.28 \mu \mathrm{g} \mathrm{mL}^{-1} \mathrm{GAE}, 0.077 \mu \mathrm{g} \mathrm{mL}^{-1} \mathrm{CE}, 0.04 \mu \mathrm{g}$ $\mathrm{mL}^{-1} \mathrm{GAE}$ and $99.5 \mu \mathrm{g} \mathrm{mL}^{-1} \mathrm{AAE}$, respectively. Among the investigated types of areke samples, Yemar areke has the highest amounts of total phenolic and followed by Debre Birhan Yekosso (brown) areke. In most cases the areke types that have additional ingredients are higher in total phenolics and antioxidant capacity than the normal (cereal). However, there are some anomalies such as Addis Ababa Yekosso, Butagira Yekosso and Debre Birhan Yekosso (white) areke which have negative antioxidant capacity. This is most probably the expected one unless these 
ingredients are combined after the distillation of areke is over using the distillate as extracting solvent (Table 2).

The result obtained in this study is comparable with the report on total phenolic contents of spirits, $0-22 \mu \mathrm{g} \mathrm{mL}^{-1} \mathrm{GAE}$ [26]. Both spirits and areke have low content of total phenolics. The reasons are the depletion of phenolic compounds present in the raw materials with the high temperatures used in the distillation process while spirits were produced. Furthermore, the volatility of phenolic compounds is lower than that of ethanol and specific aroma compounds, that is why during the distillation process phenolic compounds do not accumulate in spirit drinks [26].

The antioxidant results of areke samples are in agreement with the low antioxidant activities of pure distillates determined by DPPH and FRAP assays. Rum, vodka, gin and other distillates showed no antioxidant behavior [33] or have negative values which is consistent with the low concentrations of phenolic compounds [34]. Values obtained by DPPH method were negative due the ethanol prooxidant activity and enhanced free radical formation [26].

\section{Fermented beverages}

The fermented beverages, non-gesho and with gesho phenolics and antioxidant assays are given in Table 3-6.

Table 3. Total phenolics, total flavonoids, total tannins and antioxidant capacity of non-gesho fermented samples.

\begin{tabular}{|l|c|c|c|c|}
\hline $\begin{array}{l}\text { Types of } \\
\text { samples }\end{array}$ & $\begin{array}{c}\text { Total phenolics } \\
{\left[\mu \mathrm{g} \mathrm{mL} \mathrm{m}^{-1} \mathrm{GAE}\right]}\end{array}$ & $\begin{array}{c}\text { Total flavonoids } \\
{\left[\mu \mathrm{gL}^{-1} \mathrm{CE}\right]}\end{array}$ & $\begin{array}{c}\text { Total tannins } \\
{\left[\mu \mathrm{g} \mathrm{mL} \mathrm{gAE}^{-1} \mathrm{GA}\right.}\end{array}$ & $\begin{array}{c}\text { Antioxidant capacity } \\
{\left[\mu \mathrm{gL}^{-1} \mathrm{AAE}\right]}\end{array}$ \\
\hline Keribo & $14.9 \pm 0.04$ & $2.62 \pm 0.01$ & $0.68 \pm 0.08$ & $39.2 \pm 1.32$ \\
\hline Sample 1 & $12.4 \pm 0.02$ & $2.77 \pm 0.01$ & $4.01 \pm 0.13$ & $39.2 \pm 1.32$ \\
\hline Sample 2 & $11.8 \pm 0.03$ & $2.65 \pm 0.01$ & $4.98 \pm 0.03$ & $39.2 \pm 1.32$ \\
\hline Sample 3 & $10.4 \pm 0.01$ & $2.59 \pm 0.01$ & $3.66 \pm 0.03$ & $90.1 \pm 5.24$ \\
\hline Sample 4 & $12.1 \pm 0.03$ & $2.61 \pm 0.05$ & $4.60 \pm 0.02$ & $62.9 \pm 1.89$ \\
\hline Sample 5 & $10.9 \pm 0.02$ & $2.61 \pm 0.05$ & $4.36 \pm 0.01$ & $62.8 \pm 5.42$ \\
\hline Sample 6 & $12.2 \pm 0.14$ & $2.56 \pm 0.01$ & $0.25 \pm 0.02$ & $42.0 \pm 1.01$ \\
\hline Birz & $10.5 \pm 0.02$ & $2.57 \pm 0.01$ & $0.41 \pm 0.02$ & $52.5 \pm 1.70$ \\
\hline Sample 1 & $11.0 \pm 0.08$ & $2.56 \pm 0.01$ & $0.31 \pm 0.08$ & $63.1 \pm 1.12$ \\
\hline Sample 2 & $11.1 \pm 0.02$ & $2.56 \pm 0.01$ & $0.59 \pm 0.05$ & $50.7 \pm 0.32$ \\
\hline Sample 3 & $8.56 \pm 0.06$ & $0.90 \pm 0.09$ & $0.11 \pm 0.03$ & $217 \pm 13$ \\
\hline Sample 4 & $9.03 \pm 0.01$ & $0.75 \pm 0.01$ & $0.41 \pm 0.10$ & $180 \pm 5$ \\
\hline Borde & $10.6 \pm 2.10$ & $0.81 \pm 0.02$ & $3.67 \pm 2.07$ & $199 \pm 9$ \\
\hline Sample 1 & Sample 2 &
\end{tabular}

In this study, the total phenolic content obtained in $\mu \mathrm{g} \mathrm{mL}{ }^{-1} \mathrm{GAE}$ is: tella $(10.1-19.1)$, tej (5.8-9.5), keribo (10.4-14.9), birz (10.5-12.2), korefe (9.2-10.7) and borde (8.4-10.6). Based on the mean total phenolics content obtained the beverages are in the order: tella $>$ keribo $>$ birz $>$ korefe $>$ borde $>$ tej. According to the result obtained tella is the leading in the total phenolics content; this might be due to its more toasted grain flour (enkuro), germinated grain (bikil) and gesho (Rhamnus prenoids) in the composition [4]. Whereas tej is the least, this may be mainly by its preparation and less gesho (Rhamnus prenoids) content and nowadays by the using of sugars in place of honey during preparation [4]. The reported total phenolic contents in $\mu \mathrm{g} \mathrm{mL}^{-1}$ GAE are: in beer, 270-600 [10], 206-374 [16] and 152-339 [23]; in wine, 178-284 [16], 1893130 [21], 103-2261 [12] and 1648-4495 [35] and in dolo, 506 [16]. In all cases the reported 
total phenolics in beer and wine are higher than the total phenolic compounds in the studied traditional alcoholic beverages. This is mostly due to differences in the composition of the raw materials, storage time and brewing process [36-38].

Table 4. Total phenolics, total flavonoids, total tannins and antioxidant capacity of tella samples.

\begin{tabular}{|c|c|c|c|c|}
\hline $\begin{array}{l}\text { Types of } \\
\text { samples }\end{array}$ & $\begin{array}{l}\text { Total phenolics } \\
{\left[\mu \mathrm{g} \mathrm{mL} \mathrm{mL}^{-1} \mathrm{GAE}\right]}\end{array}$ & $\begin{array}{l}\text { Total flavonoids } \\
{\left[\mu \mathrm{g} \mathrm{mL}^{-1} \mathrm{CE}\right]}\end{array}$ & $\begin{array}{c}\text { Total tannins } \\
{\left[\mu \mathrm{g} \mathrm{mL} \mathrm{mL}^{-1} \mathrm{GAE}\right]}\end{array}$ & $\begin{array}{c}\text { Antioxidant capacity } \\
{\left[\mu \mathrm{g} \mathrm{mL}^{-1} \mathrm{AAE}\right]}\end{array}$ \\
\hline Akaki Kaliti & $13.3 \pm 0.8$ & $7.49 \pm 1.45$ & $0.87 \pm 0.05$ & $201 \pm 3$ \\
\hline Kirkos & $13.0 \pm 1.7$ & $8.09 \pm 2.15$ & $1.69 \pm 0.04$ & $109 \pm 2$ \\
\hline Lafto & $15.6 \pm 0.4$ & $5.89 \pm 0.96$ & $1.52 \pm 0.48$ & $136 \pm 1$ \\
\hline Bole & $12.2 \pm 1.3$ & $4.62 \pm 0.30$ & $0.18 \pm 0.11$ & $87.5 \pm 1.8$ \\
\hline Sendafa & $11.3 \pm 1.3$ & $4.75 \pm 0.03$ & $0.42 \pm 0.35$ & $133 \pm 4$ \\
\hline Sululta & $18.3 \pm 0.6$ & $5.41 \pm 0.06$ & $1.21 \pm 0.53$ & $110 \pm 3$ \\
\hline Arada & $11.2 \pm 1.1$ & $5.28 \pm 0.01$ & $2.29 \pm 0.07$ & $97.8 \pm 1.2$ \\
\hline Kolfe & $15.3 \pm 0.9$ & $4.97 \pm 0.01$ & $2.10 \pm 1.78$ & $186 \pm 4$ \\
\hline Burayu & $19.1 \pm 0.9$ & $4.77 \pm 0.03$ & $2.21 \pm 0.06$ & $195 \pm 1$ \\
\hline Gulele & $14.3 \pm 1.6$ & $6.10 \pm 0.04$ & $8.84 \pm 1.89$ & $151 \pm 4$ \\
\hline Addis Ketema & $12.5 \pm 0.8$ & $4.78 \pm 0.05$ & $0.28 \pm 0.24$ & $79.2 \pm 0.9$ \\
\hline Sebeta & $11.0 \pm 1.1$ & $4.89 \pm 0.01$ & $0.29 \pm 0.10$ & $74.9 \pm 2.6$ \\
\hline Yeka & $16.5 \pm 0.9$ & $5.37 \pm 0.03$ & $3.79 \pm 2.86$ & $82.7 \pm 2.3$ \\
\hline Lideta & $12.2 \pm 1.6$ & $4.40 \pm 0.01$ & $2.25 \pm 1.41$ & $75.7 \pm 3.2$ \\
\hline Dukem & $10.1 \pm 1.6$ & $5.05 \pm 0.01$ & $1.71 \pm 0.09$ & $31.6 \pm 2.1$ \\
\hline
\end{tabular}

Table 5. Total phenolics, total flavonoids, total tannins and antioxidant capacity of tej samples.

\begin{tabular}{|l|c|c|c|c|}
\hline Types of samples & $\begin{array}{c}\text { Total phenolics } \\
{\left[\mu \mathrm{g} \mathrm{mL} \mathrm{mL}^{-1} \mathrm{GAE}\right]}\end{array}$ & $\begin{array}{c}\text { Total flavonoids } \\
{\left[\mu \mathrm{g} \mathrm{mL}^{-1} \mathrm{CE}\right]}\end{array}$ & $\begin{array}{c}\text { Total tannins } \\
{\left[\mu \mathrm{g} \mathrm{mL} \mathrm{mLE}^{-1} \mathrm{GAE}\right]}\end{array}$ & $\begin{array}{c}\text { Antioxidant capacity } \\
{\left[\mu \mathrm{mL}^{-1} \mathrm{AAE}^{-}\right.}\end{array}$ \\
\hline Akaki Kaliti & $8.48 \pm 0.03$ & $3.63 \pm 0.01$ & $2.36 \pm 0.03$ & $26.5 \pm 0.1$ \\
\hline Kirkos & $7.59 \pm 0.04$ & $4.14 \pm 0.01$ & $0.93 \pm 0.41$ & $33.3 \pm 0.02$ \\
\hline Lafto & $7.42 \pm 0.29$ & $4.08 \pm 0.01$ & $0.38 \pm 0.16$ & $25.5 \pm 0.3$ \\
\hline Bole & $7.39 \pm 0.11$ & $4.11 \pm 0.01$ & $0.15 \pm 0.09$ & $27.7 \pm 0.5$ \\
\hline Sendafa & $6.06 \pm 0.20$ & $2.86 \pm 0.01$ & $0.36 \pm 0.12$ & $3.49 \pm 0.04$ \\
\hline Sululta & $6.95 \pm 0.08$ & $3.42 \pm 0.01$ & $0.65 \pm 0.17$ & $12.9 \pm 0.1$ \\
\hline Arada & $9.47 \pm 0.06$ & $3.97 \pm 0.01$ & $2.26 \pm 0.05$ & $37.7 \pm 0.5$ \\
\hline Kolfe & $6.44 \pm 0.36$ & $3.55 \pm 0.01$ & $1.08 \pm 0.19$ & $3.27 \pm 0.36$ \\
\hline Burayu & $7.33 \pm 0.52$ & $3.26 \pm 0.01$ & $1.79 \pm 0.27$ & $7.79 \pm 0.04$ \\
\hline Gulele & $6.21 \pm 0.07$ & $3.08 \pm 0.01$ & $0.27 \pm 0.07$ & $32.9 \pm 0.2$ \\
\hline Addis Ketema & $6.84 \pm 0.22$ & $3.09 \pm 0.01$ & $1.14 \pm 0.09$ & $28.5 \pm 0.1$ \\
\hline Sebeta & $6.07 \pm 0.67$ & $3.02 \pm 0.01$ & $0.51 \pm 0.60$ & $23.3 \pm 0.3$ \\
\hline Yeka & $6.87 \pm 0.06$ & $3.97 \pm 0.01$ & $0.94 \pm 0.08$ & $7.51 \pm 0.07$ \\
\hline Lideta & $8.69 \pm 0.17$ & $3.77 \pm 0.01$ & $1.77 \pm 0.30$ & $3.77 \pm 0.33$ \\
\hline Dukem & $5.77 \pm 0.08$ & $3.16 \pm 0.01$ & $0.27 \pm 0.18$ & $1.73 \pm 0.08$ \\
\hline
\end{tabular}

Table 6. Total phenolics, total flavonoids, total tannins and antioxidant capacity of korefe samples.

\begin{tabular}{|c|c|c|c|c|}
\hline $\begin{array}{l}\text { Types of } \\
\text { samples }\end{array}$ & 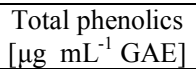 & $\begin{array}{l}\text { Total flavonoids } \\
{\left[\mu \mathrm{g} \mathrm{mL} \mathrm{mL}^{-1} \mathrm{CE}\right]}\end{array}$ & $\begin{array}{c}\text { Total tannins } \\
{\left[\mu \mathrm{g} \mathrm{mL} \mathrm{mL}^{-1} \mathrm{GAE}\right]}\end{array}$ & $\begin{array}{c}\text { Antioxidant capacity } \\
{\left[\mu \mathrm{g} \mathrm{mL}^{-1} \mathrm{AAE}\right]}\end{array}$ \\
\hline Sample 1 & $10.7 \pm 0.01$ & $3.01 \pm 0.04$ & $0.25 \pm 0.02$ & $73.9 \pm 0.8$ \\
\hline Sample 2 & $9.97 \pm 0.02$ & $2.61 \pm 0.02$ & $1.62 \pm 0.06$ & $96.5 \pm 0.4$ \\
\hline Sample 3 & $9.20 \pm 0.03$ & $2.79 \pm 0.11$ & $0.66 \pm 0.01$ & $58.4 \pm 0.2$ \\
\hline Sample 4 & $9.25 \pm 0.05$ & $2.80 \pm 0.05$ & $1.03 \pm 0.04$ & $58.3 \pm 2.5$ \\
\hline Sample 5 & $9.85 \pm 0.02$ & $2.91 \pm 0.02$ & $0.55 \pm 0.02$ & $69.2 \pm 0.5$ \\
\hline Sample 6 & $10.2 \pm 0.02$ & $2.78 \pm 0.02$ & $0.21 \pm 0.04$ & $75.1 \pm 0.2$ \\
\hline
\end{tabular}

Bull. Chem. Soc. Ethiop. 2016, 30(1) 
The total flavonoids content obtained in $\mu \mathrm{g} \mathrm{mL}^{-1} \mathrm{CE}$ is: tella (4.4-8.1), tej (2.9-4.1), keribo (2.6-2.8), birz (2.6-2.7), korefe (2.6-3.0) and borde (0.8-0.9). For mean total flavonoids the beverages are in the order: tella $>$ tej $>$ korefe $>$ keribo $>$ birz $>$ borde. The reported total flavonoids in wine range from $0.3-680$ in $\mu \mathrm{g} \mathrm{mL}^{-1} \mathrm{CE}$ [21]. Though, the obtained total flavonoids in the traditional alcoholic beverages is in the range reported by Li et al. [21], the value in wine is too high. Tella is the leading in the total flavonoids content than the rest. This might be due to its more gesho (Rhamnus prenoids) in the composition that is most probably a major source for total flavonoids.

Likewise in this investigation, the orders of the beverages based on the total tannins and antioxidant capacity are: keribo $>$ tella $>$ borde $>$ tej $>$ korefe $>$ birz and borde $>$ tella $>$ korefe $>$ keribo $>$ birz $>$ tej, respectively. Keribo is the leading in total tannins. This is most probably by its less fermentation time and preparation process [5]. In antioxidant capacity case, borde is first, this is most probably by the spices added when it is ready for serve, prepared from a wide variety of cereal crops and low alcoholic beverage [1].

In most of the investigated assays in comparison with the types of beverages analyzed, tella samples have higher values than the rest. This might be due to the amount of ingredients such as malt and hop, and their compositions [39]. Hop is known to be a major source of better antioxidant such as $p$-coumaric, caffeic, and ferulic acids [39].

The total phenolics and related assays of fermented beverages such as tella, keribo, birz, korefe, borde and tej results might be an over estimation. This might be due to the interference of the total phenolics, flavonoids, and antioxidant activity assays by substances which are present in the beverages such as sulfur dioxide, ascorbic acid, ethanol, and reducing sugars. The high concentrations of sugars (mainly glucose and fructose) and Maillard reaction products present could also interfere with these assays [32].

In all the beverages the total phenolic compounds reported in comparison with the total flavonoids and total tannins is too much and even incomparable. This has an agreement with; the majority of phenolic compounds in beer are non-tannic and non-flavonoid compounds $(98 \%$ of total phenolic compounds) such as phenolic acids [37]. The variation among beverages and samples of the same beverages were obtained at $95 \%$ confidence level. This is due to the variation in the types and amount of ingredients used, and disparity in the preparation process $[12,40]$. Moreover, the variation is dependent on the type of phenolic compounds present. For instance, flavonoids commonly constitute $>85 \%$ of the phenolics content $\left(\geq 1 \mathrm{~g} \mathrm{~L}^{-1}\right)$ in red wines. In white wines, flavonoids typically comprise $<20 \%$ of the total phenolics content $(\leq 50$ $\left.\mathrm{mg} \mathrm{L}^{-1}\right)[12]$.

\section{Relation between total phenolics and antioxidant activities of the beverages}

The relationship between total phenolics and antioxidant activities was investigated using Pearson correlation at $95 \%$ confidence level. The results obtained indicate that the non-gesho fermented beverages such as keribo $(-0.714)$, birz $(-0.686)$ and borde $(-0.212)$ have negative antioxidant correlation with the total phenolic. In contrast areke (0.609), tella (0.539), tej (0.385) and korefe (0.557) have positive correlations. In areke case the normal areke has negative correlation as reported; however, the overall correlation is positive. This is due to the phenolic compounds found in the added medicinal plants. In general, this demonstrated that the antioxidant activity of the beverages is dependent not only on the total phenolics content but also on the relative amounts of individual phenolics $[14,32]$. Furthermore, the radical scavenging capacity of a group of phenolic compounds is dependent on their structure. For instance, the radical savaging capacity of the phenolic acids decreased in the order caffeic acid $>$ protocatechuic acid $>$ ferulic acid $>$ vanillic acid $>p$-coumaric acid. From this sequence it can be concluded that cinnamic acid derivatives are better antioxidants than their benzoic acid 
counterparts. This can be explained in terms of the $\mathrm{CH}=\mathrm{CHCOOH}$ group, which participates in stabilizing the radicals of cinnamic acid derivatives by resonance [14].

\section{Statistical analysis}

The analysis of variance (ANOVA) revealed that there is a significant difference at $95 \%$ confidence level between the mean values of total phenolic, total favonoids, total tannin and antioxidant among the alcoholic beverages types and within the samples of each type. In addition, the relationship between total phenolic and antioxidant activities was investigated using Pearson correlation at $95 \%$ confidence level. The results obtained indicated that the nongesho fermented beverages keribo (-0.714), birz (-0.686) and borde $(-0.212)$ have negative antioxidant correlation with the total phenolic while areke (0.609), tella (0.539), tej (0.385) and korefe (0.557) have positive correlations. The variation in mean values of investigated parameters and the nature of correlation they have are due to the differences in preparation of the beverages, the amount and kind of ingredients used, and the types of phenolic compounds present in the raw materials and so on.

\section{CONCLUSION}

In this study the total phenolics, total flavonoids, total tannins and antioxidant activities of the beverages were investigated. In all beverages the total phenolic compounds were higher than the total flavonoids and total tannins. This showed that the majority of phenolic compounds in the beverages are non-tannic and non-flavonoids. The results obtained indicated that the distilled alcoholic beverage, areke has less antioxidant capacity and total phenolic content relative to fermented beverages. Gesho-containing fermented beverages have more total phenolic assays than the non-gesho fermented beverages. Among the fermented beverages, tella showed higher total phenolic level and antioxidant capacity than the rest. The investigation indicated that the total phenolic components of alcoholic beverages depend on the raw materials used and the brewing processes.

\section{ACKNOWLEDGMENTS}

The authors express their gratitude to the Department of Chemistry, Addis Ababa University, Ethiopia, for providing the laboratory facilities. Ayalew Debebe is thankful to Haramaya University, Ethiopia, for sponsoring his study.

\section{REFERENCES}

1. Kebede, A.; Fekadu, B.; Thor, L.; Judith, A.N. J. Food Technol. Africa 2002, 7, 59.

2. Bahiru, B.; Mehari, T.; Ashenafi, M. J. Food Technol. Africa 2001, 6, 104.

3. Fite, A.; Tadesse, A.; Urga, K.; Seyoum, E. SINET: Ethiop. J. Sci. 1991, 14, 19.

4. Debebe, G. Determination of ethanol level in beverages, Master Thesis, Addis Ababa University, Addis Ababa, Ethiopia, 2006.

5. Abawari, R.A. J. Food Resour. Sci. 2013, 2, 13.

6. Nose, A.; Hojo, M. J. Biosci. Bioeng. 2006, 102, 269

7. Madrera, R.R.; Valles, B.S. J. Chromatogr. Sci. 2007, 45, 428

8. Mahdavi, R.; Nikniaz, Z.; Rafraf, M.; Jouyban, A. Pak. J. Nutr. 2010, 9, 968.

9. Alonso-Salces, R.M.; Guyot, S.; Herrero, C.; Berrueta, L.A.; Drilleau, J.F.; Gallo, B.; Vicente, F. Food Chem. 2005, 91, 91.

10. Lugasi, A.; Hovari, J. Nahrung/Food 2003, 47, 79.

11. Drel, V.R.; Sybirna, N. Cell Biol. Int. 2010, 2, 1. 
12. Stratil, P.; Kuban, V.; Fojtova, J. Czech J. Food Sci. 2007, 26, 242.

13. Floridi, S.; Montanari, L.; Marconi, O.; Fantozzi, P. J. Agric. Food Chem. 2003, 51, 1548.

14. Komes, D.; Ulrich, D.; Ganic, K.K.; Lovric, T. Vitis 2007, 46,77.

15. Noor-Soffalina, S.S.; Jinap, S.; Nazamid, S.; Nazimah, S.A.H. Int. J. Food Sci. Technol. 2009, 44, 168.

16. Abdoul-latif, F.M.; Bayilil, R.G.; Obame, L.C.; Bassolé, I.H.N.; Dicko, M.H. Afr. J. Biotechnol. 2012, 11, 14671.

17. Sokoł-Łetowska, A.; Kucharska, A.Z.; Win'ska, K.; Szumny, A.; Nawirska-Olszan'ska, A.; Mizgier, P.; Wyspianska, D. Food Chem. 2014, 157, 533.

18. Porgal, E.; Büyüktuncel, E. Food Res. Int. 2012, 45, 145.

19. Alén-Ruiz, F.; García-Falcón, M.S.; Pérez-Lamela, M.C.; Martínez-Carballo E.; SimalGándara, J. Food Chem. 2009, 113, 53.

20. Šeruga, M.; Novak, I.; Jakobek, L. Food Chem. 2011, 124, 1208.

21. Li, H.; Wang, X.; Li, Y.; Li, P.; Wang, H. Food Chem. 2009, 112, 454.

22. Dvorakova, M.; Hulin, P.; Karabin, M.; Dostalek, P. Czech J. Food Sci. 2007, 25, 182.

23. Zhao, H.; Chen, W.; Lu, J.; Zhao, M. Food Chem. 2010, 119, 1150.

24. Koguchi, M.; Saigusa, N.; Teramoto, Y. Food Sci. Technol. Res. 2010, 16, 157.

25. Riekstina-Dolge, R.; Kruma, Z.; Karklina, D. World Acad. Sci. Eng. Technol. 2012, 6, 1063.

26. Mrvcic, J.; Posavec, S.; Kazazic, S.; Stanzer, D.; Peša, A.; Stehlik-Tomas, V. Croat. J. Food Sci. Technol. 2012, 4, 102.

27. Ashenafi, M. Ethiop. J. Biol. Sci. 2006, 5, 189.

28. Yohannes, T.; Melak, F.; Siraj, K. Afr. J. Food Sci. 2013, 7, 399.

29. Berhanu, A. Int. Food Res. J. 2014, 21, 357.

30. Abegaz, K. Afr. J. Biotechnol. 2007, 6, 1469.

31. Singleton, V.L.; Orthofer, R.; Lamuela-Raventos, R.M. Methods Enzymol. 1999, $299,152$.

32. Verzelloni, E.; Tagliazucchi, D.; Conte, A. Food Chem. 2007, 105, 564.

33. Bartoszek, M.; Polak, J. Food Chem. 2012, 132, 2089.

34. Schwarz, M.; Rodríguez, M.; Martínez, C.; Bosquet, V.; Guillén, D.; Barroso, C.G. Food Chem. 2009, 116, 29.

35. Lugemwa, F.N.; Snyder, A.L.; Shaikh, K. Antioxidants 2013, 2,110.

36. Chiva-Blanch, G.; Urpi-Sarda, M.; Rotches-Ribalta, M.; Zamora-Ros, R.; Llorach, R.; Lamuela-Raventos, R.M.; Estruch, R.; Andres-Lacueva, C. J. Chromatogr. A 2011, 1218, 698.

37. Onianwa, P.C.; Adetola, I.G.; Iwegbue, C.M.A.; Ojo, M.F.; Tella, O.O. Food Chem. 1999, $66,275$.

38. Agbor, G.A.; Moumbegna, P.; Oluwasola, E.O.; Nwosu, L.U.; Njoku, R.C.; Kanu, S.; Emekabasi, E.I.; Akin, F.; Obasi, A.P.; Abude, F.A. Afr. J. Tradit. Complement. Altern. Med. 2011, 8, 362.

39. Callemien, D.; Collin, S. Food Rev. Int. 2010, 26, 1.

40. Saura-Calixto, F.; Díaz-Rubio, M.E. Food Res. Int. 2007, 40, 613. 